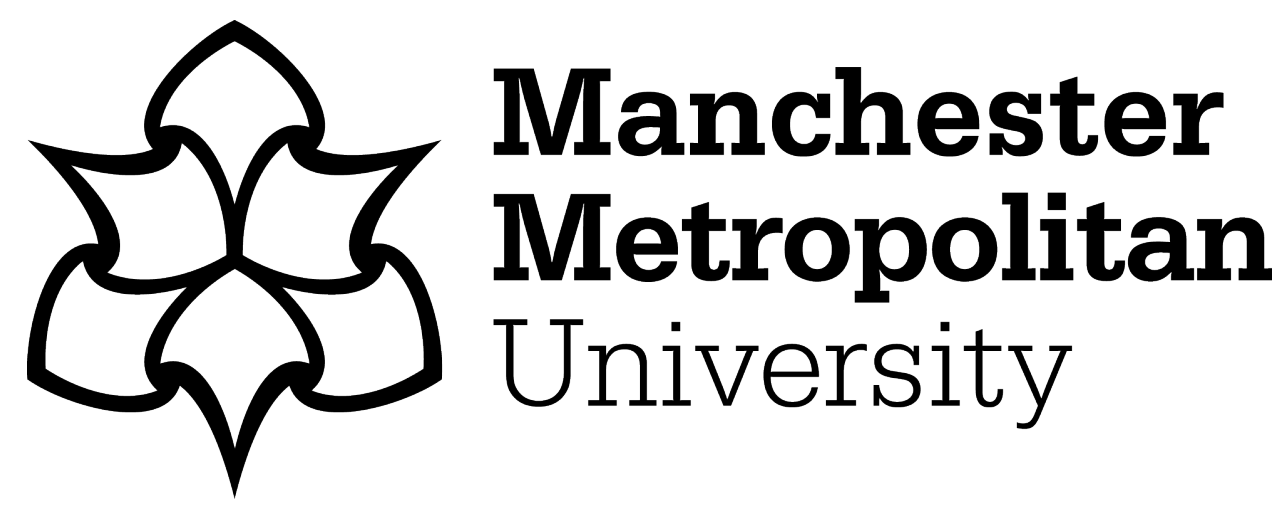

Down, Michael and Banks, Craig (2018) Freestanding Three-Dimensional Graphene Macroporous Supercapacitor. ACS Applied Energy Materials, 1 (2). pp. 891-899. ISSN 2574-0962

Downloaded from: https://e-space.mmu.ac.uk/621272/

Version: Accepted Version

Publisher: ACS

DOI: https://doi.org/10.1021/acsaem.7b00338

Please cite the published version 


\title{
Freestanding three-dimensional Graphene Macroporous Supercapacitor
}

\author{
Michael P. Down and Craig E. Banks*
}

Faculty of Science and Engineering, Manchester Metropolitan University, Chester Street, Manchester, M1 5GD, UK

*To whom correspondence should be addressed.

Email: c.banks@mmu.ac.uk; Tel: ++(0)1612471196; Fax: ++(0)1612476831

Website: www.craigbanksresearch.com 


\begin{abstract}
The capacitive performance of three-dimensional (3D) freestanding graphene macroporous material (3D-G) fabricated via a chemical vapour deposition (CVD) methodology is comprehensively investigated a potential supercapacitor material, without any mechanical support, for the first time. The capacitive performance of the 3D-G material are investigated within both aqueous electrolytic media and ionic liquids. The 3D-G exhibits a capacitance of $266 \mu \mathrm{F}$ when charged at $16.6 \mu \mathrm{A} \mathrm{g}^{-1}$ in an aqueous electrolyte; a significant improvement over a freestanding $3 \mathrm{D}$ reticulated vitreous carbon (3D-RVC) macroporous alternative in the same electrolyte and conditions which exhibits a value of only $20 \mu \mathrm{F}$.

Further improvements are demonstrated by utilising ionic liquids as the electrolytic component. $\left[\mathrm{C}_{4} \mathrm{MIM}\right]\left[\mathrm{BF}_{4}\right]$ demonstrated the capacitance across each current analysed, demonstrating values from $287 \mu \mathrm{F}$ up to $636 \mu \mathrm{F}$ for the current range $6.66 \mathrm{~mA} \mathrm{~g}^{-1}$ down to $16.6 \mu \mathrm{A} \mathrm{g}^{-1}$ and a specific energy density of $40.94 \mathrm{~W} \mathrm{~h} \mathrm{~kg}^{-1}$ and a power density of $29.33 \mathrm{~kW} \mathrm{~kg}^{-1}$. Through varying the ionic liquid we demonstrate that the capacitance of the $3 \mathrm{D}-\mathrm{G}$ is influenced by the ion mobility and the molecular mass of the electrolyte which has a profound effect upon the formation of the EDLC; higher molecular weights develop the charge double layer slower, resulting in a slightly poorer capacitive performance. The 3D-G exhibits a significant capacitive improvement over that of RVC and a nickel macropourous control (which is used as the CVD growth substrate) exhibiting remarkably high energy and power densities.
\end{abstract}




\section{Broader Context}

Supercapacitors are electrochemical energy storage systems that are finding applications in many technological fields. While the energy density of the supercapacitor is much higher than that of a conventional dielectric capacitor, it is still lower than that of batteries and fuel cells. The evolution of nanostructured materials has offered opportunities for the development of high-energy density supercapacitors. Despite this, nanomaterials are predominantly characterised as deposited on an existing electrode material as an additive or enhancement, or on a substrate, which provides the mechanical support required for the nanomaterial. Consequently, the development of an energy storage platform that applies such advanced developed materials is greatly hindered by the requirement of integrating the substrate into the final device specification and manufacture. Here, we demonstrate an approach to fabricate a symmetric electrode supercapacitor utilising a freestanding nanomaterial for the first time. A freestanding graphene macrostructure is developed to utilised the enhanced performance of the nanomaterial, without the compromise of using heavier and low performance substrates and mechanical support; the graphene macrostructure exhibits outstanding cell performance (energy and power density) over carbon macrostructure equivalents. The present work will generate a broad range of interest for those who work on graphene-based materials and energy storage devices. 


\section{Introduction}

Electrochemical capacitors, or Supercapacitors, have attracted significant attention due to their ultrahigh power density, demonstrating extremely high charge/discharge rates and excellent longevity ${ }^{1,2}$. As a result, supercapacitors have proven to be a reasonable solution to the increase in demands from the fields of portable electronics and electric vehicles. Generally, supercapacitors are identified into two categories based on the charge storage mechanisms: traditional electrochemical double layer capacitors (EDLCs) and pseudo-capacitors ${ }^{3}$. Due to low energy densities and specific capacitance of EDLCs, pseudo-capacitors are more preferable and numerous researchers have focused their effort on redox based electrode materials to improve their electrochemical performance. However, there are other alternatives to improve the performance of the supercapacitor ${ }^{3}$; for example, through utilising 3-D nanomaterials and ionic liquids, the capacitive properties can be further manipulated to improve power handling and charge storage capabilities ${ }^{2,4}$.

Nanomaterials differ from the micro and macro-sized materials not only in the scale of their characteristic dimensions, but also in the fact that they may possess advanced physical properties offering potential technological applications ${ }^{5-9}$. Through utilising 3D nanomaterials, such as graphene and metallic foams, aerogels and other cellular nanostructures, these advanced physical properties can be exploited without the use of a substrate support structure $^{10,11}$, maximising the surface area $^{12}$ and interfacial area where an electrochemical double layer can form ${ }^{13}$. They provide a format where electrical connections can be made directly to the nanomaterial and the physical size of the 3D nanomaterial allows for mechanical macro scale manipulation and handling of the material as if it were bulk, without compromising the nanoscale behavioural properties. As such, advanced 3D nanomaterials demonstrate properties ideal for electrochemical energy storage ${ }^{14}$.

Supercapacitor performance is significantly affected by the transport rates of electrons and ions. Usually such transport mechanisms can be related to the microstructure and conductive characteristics of the electrode material and the electrolytic solution used in the system. These nanomaterial macrostructures demonstrate improved properties due to porous structures and high conductivities. For example a 3D macroporous 'bubble' graphene film was fabricated by a hard template-directed assembly strategy ${ }^{15}$. The monodispersed polymethyl methacrylate (PMMA) spheres were used as the hard templates, and subsequently removed calcination at $800{ }^{\circ} \mathrm{C}$. The as-obtained graphene film showed high capacitance retention $(67.9 \%)$ when 
scanned from 3 to $1000 \mathrm{mV} \mathrm{s}^{-1}$. Despite this, the structural properties were again showed to be questionable after drying and annealing processes, where aggregation of the graphene sheet significantly reduced the specific area.

Further to this, Choi et al. fabricated 3D macroporous chemically modified graphene films using polystyrene colloidal particles as templates and subsequently removed them with toluene ${ }^{16}$. This low temperature solution method resulted in well-defined interconnected pore networks of a cellular solid structure consisting of chemically modified graphene films. The films showed good electrical conductivity $\left(1204 \mathrm{~S} \mathrm{~m}^{-1}\right)$, but in order to increase the capacitance, a layer of $\mathrm{MnO}_{2}$ was additionally deposited onto the porous films. Energy dispersive $\mathrm{x}$-ray spectroscopy (EDS) elemental maps of C, O and Mn provided evidence for the formation of a homogenous coating of $\mathrm{MnO}_{2}$ throughout the 3D macroporous framework. Due to their fast ionic transport and high electrical conductivity within the electrode, the porous $\mathrm{MnO}_{2} /$ chemically modified graphene hybrid film exhibited a high specific capacitance of 389 $\mathrm{F} \mathrm{g}^{-1}$ at $1 \mathrm{~A} \mathrm{~g}^{-1}$ and superior capacitance retention of $97.7 \%$ when scanned from 1 to $35 \mathrm{~A} \mathrm{~g}^{-1}$. An assembled device, featuring asymmetric electrode of chemically modified graphene film (anode) and a $\mathrm{MnO}_{2} /$ chemically modified graphene film (cathode), demonstrated an energy density of $44 \mathrm{~W} \mathrm{~h} \mathrm{~kg}^{-1}$ with a power density of $11.2 \mathrm{~kW} \mathrm{~g}^{-1}$ and a potential window of $2.0 \mathrm{~V}$.

Apart from fabrication approaches using polymer sphere templates, 3D macroporous films or graphene macrostructure can also be synthesized by using Ni template-directed chemical vapour deposition (CVD) method ${ }^{14}$. Zhang et al. reported a method to prepare 3D porous graphene networks by using a Ni macrostructure as a sacrificial template in a CVD process with ethanol as the carbon source. Moreover, they electrochemically deposited nickel oxide $(\mathrm{NiO})$ onto the 3D graphene networks to fabricate graphene-NiO composite electrodes for applications as a supercapacitors. The unique 3D porous structure of the graphene network with a large specific surface area allows rapid access of electrolyte ions to the $\mathrm{NiO}$ surfaces. The obtained NiO-graphene composite exhibits a high specific capacitance of $816 \mathrm{~F} \mathrm{~g}^{-1}$ at a scan rate of $5 \mathrm{mV} \mathrm{s}^{-1}$.

To date, there are no reported studies of bare/unmodified 3D freestanding graphene macrostructures explored as supercapacitor materials. This does indicate the uncertainty of the exact performance of the 3D macroporous structures given that growth substrates and platforms can provide some of the electrochemical work contributing to the overall capacitive performance. 
Each of these examples (identified above) are tested with further support mechanisms, substrates, or conduction paths and as such may not represent the true value of the macrostructure as a potential capacitor electrode material. This paper looks to quantify 3D graphene macrostructures, freestanding, without any support, for application in advanced supercapacitors, both utilising aqueous electrolytes and ionic liquid electrolytes in a symmetric supercapacitor. This investigation will be the first comprehensive study of the 3D-G for energy storage applications. The effect of varying the electrolyte is fully investigated, evaluating the properties for various hydrophobic, ion mobility, and viscous properties, of the electrolytic solution. Further to this, the performances of a nickel macrostructure, which acts the CVD growth substrate of the 3D freestanding graphene, and a reticulated vitreous carbon macrostructure are also investigated as control experiments, for the first time the 3D freestanding graphene macrostructure gives rise to exceptional power and energy density. 


\section{Experimental Section}

All chemicals utilised were of analytical grade (or higher) and were used, as received, from Sigma- Aldrich without any further purification. All aqueous solutions were prepared with deionised water of resistivity not less than $18 \mathrm{M} \Omega \mathrm{cm}$. Non aqueous solutions were prepared using one of three Room Temperature Ionic Liquids (RTILs): 1-butyl-3methylimidazoliumtetra fluoroborate, $\left[\mathrm{C}_{4} \mathrm{MIM}\right]\left[\mathrm{BF}_{4}\right]$; 1-butyl-3-methylimidazolium hexafluorophosphate, $\quad\left[\mathrm{C}_{4} \mathrm{MIM}\right]\left[\mathrm{PF}_{6}\right] ; \quad$ and 1-butyl-3-methylimidazolium bis(trifluoromethylsulfonyl)imide, $\left[\mathrm{C}_{4} \mathrm{MIM}\right]\left[\mathrm{NTf}_{2}\right]$.

Voltammetric measurements were performed using an 'Autolab - $\mu$ Autolab Type III' (Metrohm Autolab, The Netherlands) potentiostat. All measurements reported herein were performed utilising a 2-electrode measurement system, where the corresponding counter and working electrodes are comprised of the same material. The following electrode materials, all commercially sourced, were utilised in this work as follows: freestanding 3D graphene macrostructure (3D-G); freestanding 3D carbon (3D-RVC) and a 3D freestanding 3D nickel macrostructure (see below for further details of these materials). A symmetric two electrode system was employed, utilising two 3D macrostructure electrodes, of the same type, aided by the application of a parallel capacitive circuit ${ }^{17}$, which reduces the ambiguity of the analysis of the capacitive properties and performance of the electrode material. The $3 \mathrm{D}$ macrostructures are tested as supercapacitors as electrodes by means of galvanostatic DC analysis, providing charge/discharge characteristics of the $3 \mathrm{D}$ macrostructural electrodes, in a $0.1 \mathrm{M} \mathrm{H}_{2} \mathrm{SO}_{4}$ aqueous solution and each of the ionic liquids. Typically, the capacitance, $C_{\text {total }}$, of the supercapacitor is evaluated from the slope of the charge/discharge cycles using the following:

$$
C_{\text {total }}=\frac{I}{(d V / d t)}
$$

where $I$ is the current applied, $V$ is the potential measured over time, $t$.

In order to perform capacitive analysis of the electrodes, a novel capacitive circuit proposed by our group was integrated into the analysis ${ }^{17}$. The benefit of this parallel capacitor is that the resulting charge/discharge curve is significantly easier to interpret. The system demonstrates a linear, or near linear, change in potential over time. As a result of a supporting capacitor ensuring the charge of the system does not begin to saturate, which cause the plateau of the potential frequently observed in such analyses. The charge-discharge behaviour of the total 
system is then related to the total capacitance of the parallel circuit. The total capacitance being then the sum of the capacitance of the systems components:

$$
C_{\text {total }}=C_{1}+C_{2}+C_{3} \ldots=\sum_{i} C_{i}
$$

The capacitance of the circuit can therefore be determined as the sum of the capacitance of the working electrode, $C_{W E}$, the counter electrode, which is assumed to be equal to $C_{W E}$, and the capacitance of the parallel circuit, $C_{\text {Known }}$, such that:

$$
C_{\text {total }}=C_{\text {Known }}+2 C_{W E}
$$

and therefore:

$$
C_{W E}=\frac{1}{2}\left(C_{\text {total }}-C_{\text {known }}\right)
$$

and from equation 1 :

$$
C_{W E}=\frac{1}{2}\left(\frac{I}{d V / d t}-C_{\text {known }}\right)
$$

where $C_{W E}$ is the capacitance exhibited by the working electrode, $d V / d t$ is the slope of the potential of the total device with regards to time.

On many occasions, the slop of $V$ against $t$ does not have a distinct uniform value, rather a range of decreasing values as the gradient plateaus at the charge saturation point of the capacitor. The interpretation of the real capacitance of the electrode is therefore difficult, providing results that are incomparable to other studies. The addition of the capacitor is for this exact purpose; to produce a linear response from the potential, thus allowing an exact and constant value for $d V / d t$ to be determined and provide a comparable and repeatable analysis. The approach here is a standardised approach for the development and characterisation of supercapacitors, reducing complications with the interpretation of the experimental data.

The capacitive circuit is inserted parallel with the working and counter electrode during capacitive charge/discharging cycles, improving the linearity, and consequently the reliability, of the results and is accounted for the post-processing analysis of data. For this study, unless 
otherwise stated, the parallel capacitance is kept constant at $620 \mu \mathrm{F}$. The galvanostatic charging current is varied for each electrode/electrolyte combination from 0.5 to $50 \mu \mathrm{A}$, for the aqueous solution and at 0.5 to $200 \mu \mathrm{A}$ for the ionic liquids. This charging current has a period of 15 seconds before polarity is reversed for discharging. The electrode/electrolyte combinations are cycled over 100 cycles to provide the system time to settle and a large data set to provide a reasonable average.

The freestanding 3D graphene macrostructure materials were manufactured as reported and described previously ${ }^{18}$, which involves using a nickel 3D macrostructure as a skeletal structure, which defines the geometric features and macrostructural properties, such as pore size. The graphene is grown on the nickel lattice via means of chemical vapour deposition, with a methane atmosphere of $1 \%$ at a growth temperature of $1000{ }^{\circ} \mathrm{C}$ under ambient pressure. The underlying nickel support structure is coated in Poly(methyl methacrylate), PMMA, to reduce the potential of collapsing during the etching of the nickel. The nickel is slowly etched in $3 \mathrm{M}$ $\mathrm{HCl}$ at $80{ }^{\circ} \mathrm{C}$ for 12 hours. The PMMA is then removed via washing the sample with hot acetone. It should be noted that if the PMMA is not used in this process the freestanding 3D graphene structure is significantly deformed during the nickel etching process, however its inclusion provides mechanical support to the structure whilst submerged in the etchant.

To confirm the removal of the nickel and PMMA, EDX and XPS of the samples are conducted. XPS was conducted on the 3D freestanding graphene macroporous structure (3D-G) which reveals the 3D-G to be composed of $95 \%$ carbon and $5 \%$ oxygen. the low $\mathrm{O} / \mathrm{C}$ ratio for the $3 \mathrm{D}-\mathrm{G}$ is near that of true pristine graphene ${ }^{19}$. Note traces of nickel could not be identified at $710 \mathrm{eV}$. Additionally, whilst the XPS shows oxygenation in the carbon structure, Raman does not exhibit any D band, this is most probably due to the higher/larger surface area analysed in XPS $(400 \mu \mathrm{m})$ in comparison with the laser spot of Raman. It is clear that given the formation of the structure, that is a graphene film encapsulating the nickel substrate onto which it is grown, the macrostructure must be broken, incomplete or defective to allow the etchant to penetrate and remove the nickel. This is evident in the SEM images presented in Figure 1, which appears not to be substantially extrusive to dramatically change the resulting freestanding macrostructure.

Following the fabrication of the $3 \mathrm{D}$ graphene macrostructure, the material was carefully cut to shape with a sharp cutting tool into a geometry with an average dimension of $15.0 \mathrm{~mm} \times 10.0$ $\mathrm{mm} \times 0.60 \mathrm{~mm}$, for use as an electrode providing enough material for a good electrical 
connection and submersion into the electrolyte without any further modification. For comparison, a freestanding 3D reticulated vitreous carbon (3D-RVC) - a macro-porous, glassy carbon material, with the average dimensions $13.0 \mathrm{~mm} \times 8.00 \mathrm{~mm} \times 5.60 \mathrm{~mm}$ - was also tested (The Electrosynthesis Company Inc., Lancaster, NY, USA) which has been characterised and extensively utilised in electrochemistry ${ }^{20}$, particularly applications in industrial scale ups ${ }^{21}$. Also a sample of the nickel macrostructure on which the graphene was grown (Graphene Laboratories Inc.), cut to the dimensions $13.0 \mathrm{~mm} \times 4.00 \mathrm{~mm} \times 0.80 \mathrm{~mm}$. Other than dicing for use as an electrode, these structures were utilised as received from the supplier without any further physical or chemical modification.

Given the different dimensions of each of the structures, capacitance of each of the electrodes presented are normalised into volumetric units, $\mu \mathrm{F} \mathrm{cm}^{-3}$, to allow direct comparison of the capacitive performance. Additionally, since the average pore size of the $3 \mathrm{D}$ graphene structures is shown to be $300 \mu \mathrm{m}$, shown in Figure 1, whereas that of the 3D-RVC carbon is $400 \mu \mathrm{m}$, a correction factor is applied by dividing the capacitance of the graphene structure by a factor of $4 / 3$. This allows a direct comparison per unit volume of conducting material accounting for vacancies in the cellular macrostructure.

SEM, Raman spectroscopy and XPS analysis the respective structures were used as fabricated or as received from the supplier without any further modification. SEM images were obtained with a JEOL JSM-840 model equipped with and X-ray detector for EDX microanalysis. Raman spectra were recorded using LabRam (Jobin-Ivon) with a confocal microscope $(\times 100$ objective) spectrometer with He-Ne laser at $632 \mathrm{~nm}$ wavelength at low power levels $(0.9 \mathrm{~mW})$ to avoid any heating effects. 


\section{Results and Discussion}

First, consideration is given to the physical macrostructure of the freestanding macrostructures via SEM. Figure 1, and ESI figures 2 and 3 show SEM images of the freestanding 3D-G, 3D nickel and the freestanding 3D-RVC respectively. The morphological similarities between the graphene and the nickel structures onto which it is grown are apparent. Both cellular macrostructures have cell diameters of $200 \mu \mathrm{m}$, and it is notable is the continuity of structure following the manufacturing process given the similarities between the macrostructures and geometries of the materials. The obvious 'wrinkling' of the graphene surface is a result of internal stresses associated with thin film deposition, where contrasting thermal properties induce stresses in interfacial connections during cooling in the CVD process (see experimental section). Breakages, as shown inset into Figure 1, are unavoidable given the manufacturing and dicing of the samples, and are also found after the etching process to remove the Ni substrate from. A benefit of such features, breakages and defects in the structure is the increase in electron transfer at the 3D graphene macrostructure as these "defects" will reveal edge plane sites and defects of the grown graphene. The 3D-RVC demonstrates a significantly different cellular structure, with various brittle edged cell of sizes ranging from $100 \mu \mathrm{m}$ to $800 \mu \mathrm{m}$. This is likely a consequence of the manufacturing process, where the polymerisation of a resin combined with foaming agents creates a cellular structure based on the geometries of varying structural cells, dictated by conditions and properties of the foaming agents, before carbonisation of the resulting structure.

Characterisation of the 3D-G via Raman spectroscopy is presented in Figure $1 \mathrm{~B}$, where the two characteristic peaks at $1581 \mathrm{~cm}^{-1}$ and $2684 \mathrm{~cm}^{-1}$, due to the $\mathrm{G}$ and $2 \mathrm{D}\left(\mathrm{G}^{\prime}\right)$ bands, are shown respectively. The asymmetric appearance of the $2 \mathrm{D}\left(\mathrm{G}^{\prime}\right)$ indicates that the graphene is likely comprised of few to multi-layered graphene, of the order of 2-8 layers, with a full width half maximum of $32.1 \mathrm{~cm}^{-1} 22$, consistent with the SEM images shown in Figure $1 \mathrm{~A}$. The negligible $\mathrm{D}$ band indicates that the graphene is largely high quality featuring no significant defects. The observations presented here are in agreement with other quasi-graphene studies, where the sample deviates from mono-layered graphene is far from being classified as bulk graphite. The 3D-G is compared to the 3D-RVC, also shown in Figure 1, which demonstrates the D and G peaks which significantly dwarf any evidence of the $2 \mathrm{D}\left(\mathrm{G}^{\prime}\right)$ peak. 


\section{Capacitive analysis in aqueous electrolytes}

The capacitive properties of the 3D-G are first considered in an aqueous solution, being compared and benchmarked to 3D reticulated vitreous carbon as a standard. It should be noted that in each of the experiments a symmetric arrangement is utilised, ensuring that both the working and counter electrodes are of the same material. The macrostructures are connected as the working and counter electrodes and submerged into the electrolyte in a pouch, as reported by Down et al. ${ }^{23}$. The flexibility of the pouch allow the graphene to be submerged into the solution with negligible mechanical manipulation without the macrostructures relying on a supporting material, a process particularly important with the $3 \mathrm{D}-\mathrm{G}$ given the hydrophobicity of the material. The cyclic voltammogram of the graphene is shown in Figure 2A. The voltammograms are indicative of the capacitance of the supercapacitor electrodes, the larger the volume indicate a higher capacity for storing charge.

In order to evaluate the capacitive performance of the structures each sample is subjected to charging currents from $0.5 \mu \mathrm{A}\left(16.6 \mu \mathrm{A} \mathrm{g}^{-1}\right)$ to $50 \mu \mathrm{A}\left(1.66 \mathrm{~mA} \mathrm{~g}^{-1}\right)$ utilising a parallel capacitor of $620 \mu \mathrm{F}$. The charge/discharge properties of the macrostructures, without any parallel capacitor, are presented in Figure 2B. Both materials demonstrate charging properties which generate an ambiguity in the analysis of the results. The non-linear response to of the electrical potential across the two electrodes demonstrates the natural charge saturation associated with electrical supercapacitors. As a result the determination of the capacitance of the macrostructures is dependent on the point at which the analysis is carried out. This behaviour is overcome by utilising the parallel capacitor demonstrated by Kampouris et $a l^{24}$. Through utilising the parallel capacitive circuit the system demonstrate a much more linear response, providing only one gradient related to the total capacitance of the system. Figure 2D shows the response of the system for currents increase from $16.6 \mu \mathrm{A} \mathrm{g}^{-1}$ to $1.66 \mathrm{~mA} \mathrm{~g}^{-1}$. The potential range varies from $0.33 \mathrm{~V}$ down to $0.12 \mathrm{~V}$ over the 15 second charge period, for 50 and $0.5 \mu \mathrm{A}$ charging current respectively, indicating an increase in capacitance with the applied current; a trend associated with the charge leakage in supercapacitors. The capacitance of the 3D graphene macrostructure varies from $266 \mu \mathrm{F} \mathrm{g}^{-1}$ down to $120 \mu \mathrm{F} \mathrm{g}^{-1}$ for charge/discharge currents $16.6 \mu \mathrm{A} \mathrm{g}^{-1}$ to $1.66 \mathrm{~mA} \mathrm{~g}^{-1}$, respectively. This is a significant improvement when compared to the capacitive performance of the 3D-RVC, which demonstrates values of $20 \mu \mathrm{F}$ $\mathrm{g}^{-1}$ down to only $9 \mu \mathrm{F} \mathrm{g}^{-1}$ over the same current range. This is consequence of the increased number active material in the graphene macrostructure when compared to the 3D-RVC. Where the 3D-G is completely freestanding; the support having been etched away, the electrolyte can 
interact with the entirety of the material, forming larger capacitive volumes; whereas the 3DRVC consists of a carbonised glassy amorphous material with a random structure of thicker cell sizes and wall, with consequently less active material per unit volume, and hence mass. The increased density of the 3D-RVC also damages the capacitive performance per unit gram, ensuring the performance is an order of magnitude less than that of the graphene macrostructure.

If we consider the performance of both the graphene and the 3D-RVC it is clear that the graphene macrostructure demonstrates significantly improved performance, as a result of it's truly freestanding structure, the propensity for active edge sites and the high density of pores in a light manageable structure. The hydrophobicity of the macrostructure can be overcome by submerging the macrostructures in a flexible pouch allowing slight mechanical manipulation without incurring damage to the electrodes, providing relative support without compromising the freestanding nature of the structure of the 3D graphene macrostructure.

Following the above insights, we next move to exploring the use of non-aqueous media, in the form of Room Temperature Ionic Liquids (RTILs). Due to their reported archetypal properties of high intrinsic conductivity, low volatility, high polarity, high thermal stability and wide electrochemical windows, they demonstrate useful and unique electrochemical properties; giving rise to their beneficial use in gas sensors, Li-ion batteries, supercapacitors and as electrode composites.

\section{Capacitive analysis in ionic liquids}

First due attention is given to the electrochemical behaviour of the electrodes, when submerged in the ionic liquids over a potential range which can be considered applicable to reasonable supercapacitors. The electrolytes considered here are 1-butyl-3-methylimidazoliumtetra fluoroborate, $\left[\mathrm{C}_{4} \mathrm{MIM}\right]\left[\mathrm{BF}_{4}\right]$; 1-butyl-3-methylimidazolium hexafluorophosphate, $\left[\mathrm{C}_{4} \mathrm{MIM}\right]\left[\mathrm{PF}_{6}\right]$; and 1-butyl-3-methylimidazolium bis(trifluoromethylsulfonyl)imide, $\left[\mathrm{C}_{4} \mathrm{MIM}\right]\left[\mathrm{NTf}_{2}\right]$, over the potential window -4.0 to $4.0 \mathrm{~V}$. Figure 3 shows the cyclic voltammograms for the graphene macrostructures for each of the ionic liquids. As mentioned previously the volume of the voltammogram is indicative of the capacitive performance of the system, in this case there are some significant features apparent in at least one of the voltammograms. The voltammogram for $\left[\mathrm{C}_{4} \mathrm{MIM}\right]\left[\mathrm{PF}_{6}\right]$ indicates a typical response, demonstrating no significant peaks indicating non or negligible pseudo-capacitive effects are 
occurring. It does however demonstrate the smallest volume of all the voltammograms indicating the poorest capacitive performance.

The ionic liquid $\left[\mathrm{C}_{4} \mathrm{MIM}\right]\left[\mathrm{BF}_{4}\right]$ demonstrates a significant improvement in terms of the potential capacitance, demonstrating a volume of almost double that of $\left[\mathrm{C}_{4} \mathrm{MIM}\right]\left[\mathrm{PF}_{6}\right]$, however it also begins to demonstrate potential peaks and characteristics which may indicate pseudo-capacitive properties. The voltammogram for $\left[\mathrm{C}_{4} \mathrm{MIM}\right]\left[\mathrm{BF}_{4}\right]$ begins to demonstrate some deviations from the typical behaviours, demonstrating a couple of peaks and a number of fluctuations and irregularities that can be attributed to oxidation of various species. The $\left[\mathrm{C}_{4} \mathrm{MIM}\right]\left[\mathrm{NTf}_{2}\right]$ demonstrates significant oxidation and reduction peaks at 1.1 and $-0.9 \mathrm{~V}$ respectively. The values here represent the region in which the pseudo-capacitive properties would positively influence the performance of the supercapacitor. Such pseudo-capacitive properties can greatly improve the capacitance provided they are operated within the potential limits of the peaks, however outside of this potential window such pseudo-capacitors have a propensity to perform relatively poorly. As a result this limits the potential range of such systems, and hence the applications of the electrode material and electrolyte in real life applications.

In order to observe and quantify the capacitive performance of the graphene macrostructure it must be exposed to charging conditions comparable to capacitors or pseudo-capacitors. The 3D-G electrodes are exposed to charging and discharging currents from 0.5 to $200 \mu \mathrm{A}$, which should provide potential ranges which exist within the potential of pseudo-capacitive region of the observed $\left[\mathrm{C}_{4} \mathrm{MIM}\right]\left[\mathrm{NTf}_{2}\right]$ oxidation and reduction peaks, and potential ranges which exceed this, providing a relative performance comparison. Figure 3 shows the natural charge discharge properties of the graphene macrostructure in each of the ionic liquids considered, the current applied in this case is $1 \mu \mathrm{A}$, which provides a potential ranging from -0.38 to $0.35 \mathrm{~V}$, and hence exists well within the potential window for the pseudo-capacitive performance illustrated by the $\left[\mathrm{C}_{4} \mathrm{MIM}\right]\left[\mathrm{NTf}_{2}\right]$ ionic liquid. Despite this the performance of $\left[\mathrm{C}_{4} \mathrm{MIM}\right]\left[\mathrm{NTf}_{2}\right]$ as determined by the inverse of the potential over time, is shown to be by far the worst over this analysis. The inverse gradient, as shown in Equation 5, is inversely proportional to the capacitance of the working electrode. As such the electrode with the highest peak to peak range demonstrates the worst capacitive performance, in this case $\left[\mathrm{C}_{4} \mathrm{MIM}\right]\left[\mathrm{NTf}_{2}\right]$. Whereas $\left[\mathrm{C}_{4} \mathrm{MIM}\right]\left[\mathrm{BF}_{4}\right]$ demonstrates the smallest potential range demonstrating the best performance of the ionic liquids investigated. 
This is summarised in the quantisation of the capacitive values for the systems. The ionic liquid $\left[\mathrm{C}_{4} \mathrm{MIM}\right]\left[\mathrm{BF}_{4}\right]$ demonstrated the highest capacitance across each current analysed, demonstrating values from $287 \mu \mathrm{F} \mathrm{g}^{-1}$ up to $636 \mu \mathrm{F} \mathrm{g}^{-1}$ for the current range $16.6 \mu \mathrm{A} \mathrm{g}^{-1}$ to 6.66 $\mathrm{mA} \mathrm{g}^{-1}$. [C $\left.\mathrm{C}_{4} \mathrm{MIM}\right]\left[\mathrm{NTf}_{2}\right]$ was slightly lower for each current with values from 252 up to 559 $\mu \mathrm{F} \mathrm{g} \mathrm{g}^{-1}$ for the current range $16.6 \mu \mathrm{A} \mathrm{g}^{-1}$ to $6.66 \mathrm{~mA} \mathrm{~g}^{-1}$.

It was proposed in the consideration of such graphene macrostructures for the detection of electrochemical signatures that the diffusional properties of the ionic liquids was a significant contributor to the differential performances of these three ionic liquids ${ }^{25}$. In this, they hypothesized that the viscosities, reported as $\left[\mathrm{C}_{4} \mathrm{MIM}\right]\left[\mathrm{NTf}_{2}\right]=52 \mathrm{mPa} \mathrm{s} ;\left[\mathrm{C}_{4} \mathrm{MIM}\right]\left[\mathrm{BF}_{4}\right]=$ $112 \mathrm{mPa} \mathrm{s}$; and $\left[\mathrm{C}_{4} \mathrm{MIM}\right]\left[\mathrm{PF}_{6}\right]=371 \mathrm{mPa}$ s (all at $\left.\mathrm{T}=293 \mathrm{~K}\right)^{26}$, were inversely proportional to the voltammetric responses in the detection of the electrochemical signature of the ionic solutions. In this case, the ionic liquids were used to improve the response of the detection of molecules, when compared to the detection in aqueous media. As a result the viscosity was directly impacting the transportation of the desired molecule through the medium; a low viscosity allows easier travel through the solution, towards each electrode and improved the respective signals; whereas a high viscosity increases the resistance of the movement, reducing the response.

This trend does not seem applicable in the case of the supercapacitive properties of the liquids in this study. This is likely a result of the pseudo-capacitive properties of the system providing non-uniform field effects over time; as the potential fluctuates over time do to the oxidation and reduction peaks the formation of a uniform double layer is not guaranteed, potentially negatively affecting the capacitive performance of the material. Consideration should also be given to the molecular structures and molecular weights of the ionic liquids. Given the formation of a capacitive double layer is a physicochemical process driven by the electrostatic forces on charged ions in an electric field, the mass of the molecule is an indicator of the acceleration in the field, as per Newtonian mechanics. The molecular masses of the ionic liquids are as follows: $\left[\mathrm{C}_{4} \mathrm{MIM}\right]\left[\mathrm{NTf}_{2}\right]=419.36 \mathrm{~g} \mathrm{~mol}^{-1} ;\left[\mathrm{C}_{4} \mathrm{MIM}\right]\left[\mathrm{PF}_{6}\right]=284.19 \mathrm{~g} \cdot \mathrm{mol}^{-1}$; and $\left[\mathrm{C}_{4} \mathrm{MIM}\right]\left[\mathrm{BF}_{4}\right]=226.02 \mathrm{~g} \mathrm{~mol}^{-1}$. Considering the correlation with the molecular weight and the capacitive analysis there is a clear relation between the molecular weight and formation of a capacitive double layer over a fixed time. Further to this, when considering the size of the molecules, steric hindrance can also play a part impacting the mobility of the molecule, the formation of the double layer, and effectively the thickness of the resulting double layer capacitance. 
Given that an analysis of this nature, utilising a parallel capacitive circuit to determine the true capacitive value of the electrode material, has not been widely utilised, the performance of the graphene macrostructure should be compared to that of the 3D-RVC as a standard. Furthermore, the nickel, onto which the 3D-G has been grown, is tested for further comparison. For this study only the best performing ionic liquid, [ $\left.\mathrm{C}_{4} \mathrm{MIM}\right]\left[\mathrm{BF}_{4}\right]$, is utilised. Figure 4 shows the capacitance for each of the macrostructures, the 3D freestanding Graphene macrostructure $\left[\mathrm{C}_{4} \mathrm{MIM}\right]\left[\mathrm{BF}_{4}\right]$. As reported here, the $3 \mathrm{D}-\mathrm{G}$ demonstrates capacitance values from $287 \mu \mathrm{F} \mathrm{g} \mathrm{g}^{-1}$ up to $636 \mu \mathrm{F} \mathrm{g}^{-1}$ for the current range $16.6 \mu \mathrm{A} \mathrm{g}^{-1}$ to $6.66 \mathrm{~mA} \mathrm{~g}^{-1}$, when compared to $55 \mu \mathrm{F} \mathrm{g}^{-1}$ up to $122 \mu \mathrm{F} \mathrm{g}^{-1}$ for the $3 \mathrm{D}-\mathrm{RVC}$ and $20 \mu \mathrm{F} \mathrm{g}$ ' to $45 \mu \mathrm{F} \mathrm{g} \mathrm{g}^{-1}$ for the nickel macrostructure over the same current range.

Further to this the freestanding graphene macrostructures demonstrates impressive energies and power densities. For the $\left[\mathrm{C}_{4} \mathrm{MIM}\right]\left[\mathrm{BF}_{4}\right]$ ionic liquid the system demonstrated a maximum energy density up to $40.94 \mathrm{Wh} \mathrm{kg}^{-1}$, corresponding to a power density of $22.23 \mathrm{~kW} \mathrm{~kg}^{-1}$. Figure 5 illustrates this performance with respect to several other studies; comparing the freestanding graphene materials to Poly (Ionic Liquid) - Modified reduced graphene oxide electrodes ${ }^{27}$; a symmetrical graphene based supercapacitor ${ }^{28}$; a symmetrical supercapacitor using reduced graphene oxide, modified with ruthenium oxide and polyaniline ${ }^{29}$; an asymmetric supercapacitors of graphene and $\mathrm{MnO}_{2}$ nanowires; a manganese oxide activated carbon hybrid capacitor $^{30}$; a supercapacitor utilising metal oxide nanowires/carbon nanotube thin film electrodes $^{31}$. In this figure it can be seen that the freestanding graphene macrostructure performs competitively in both the energy and power performance with regards to these materials. It should also be noted that these studies the electrode materials are not freestanding and require further mechanical support. With this in mind the performance of the freestanding graphene macrostructure demonstrates this performance without the requirement of a growth substrate reducing the mass required in a final device.

To summarise, the 3D freestanding graphene macrostructure has been shown to have pseudographene or few layered graphene properties (see characterisation). The Raman spectroscopy of the macrostructure indicates a slight asymmetry in the $2 \mathrm{D}\left(\mathrm{G}^{\prime}\right)$ peak, a trait indicative of the graphene harbouring small flaws, defects or few/multiple layers. The structure of the 3D-G, defined by the growth mechanism and substrate, has been shown to demonstrate cellular dimensions, i.e. pore size and feature size, almost identical to that of the nickel macrostructure onto which it is grown. There is little to no evidence that any damage is incurred during the etching away of the nickel macrostructure. The presence of wrinkles and surface features 
demonstrate the effect of residual stress in high temperature deposition techniques. In terms of capacitive properties it is clear that the graphene macrostructure has significant potential, along with the ionic liquids. It is clear however that careful consideration should be given to the choice of ionic liquid and electrodes in order to match the high performance electrode with a mobile molecule which can form a reliable double layer efficiently. 


\section{Conclusions}

We have explored, for the first time, the capacitive properties of graphene without the complication of ambiguity in the analysis of the charge and discharge behaviours. This has allowed us to not only set a standard in the approach of characterisation of advanced materials in energy storage, but also demonstrate conclusively the behaviours of graphene in both aqueous and non-aqueous based energy storage applications. Where typically capacitive testing utilising the charge discharge cycles demonstrate peak to peak features of non-consistent gradients, which generates an ambiguity in the analysis and potential point of exploitation to quote values of non-realistic capacitances. This analysis allows one gradient to be taken as a representative value for the entire system limiting misinterpretation. This analysis allows the direct comparison of the true values of capacitance of graphene, nickel and 3D-RVC macrostructures, in ionic liquids without any misconception of the point of analysis.

This study conclusively demonstrates the advanced performance of graphene macrostructure as a supercapacitor electrode, in both aqueous and no aqueous media. The effect of the varying molecular masses of ionic liquid is understood to have a profound and significant impact on the performance of the supercapacitor. The 3D-G demonstrates a capacitance of $266 \mu \mathrm{F} \mathrm{g} \mathrm{g}^{-1}$ when charged at $16.6 \mu \mathrm{A} \mathrm{g}^{-1}$ in an aqueous electrolyte. A significant improvement from the $3 \mathrm{D}-\mathrm{RVC}$ in the same solution and conditions which demonstrated a value of only $20 \mu \mathrm{F} \mathrm{g} \mathrm{g}^{-1}$. Further improvement is demonstrated by utilising ionic liquids as the electrolytic component. $\left[\mathrm{C}_{4} \mathrm{MIM}\right]\left[\mathrm{BF}_{4}\right]$ demonstrated the capacitance across each current analysed, demonstrating values from $287 \mu \mathrm{F} \mathrm{g}^{-1}$ up to $636 \mu \mathrm{F} \mathrm{g}^{-1}$ for the current range $6.66 \mathrm{~mA} \mathrm{~g}^{-1}$ down to $16.6 \mu \mathrm{A} \mathrm{g}^{-}$ ${ }^{1}$. Through tailoring the ionic liquid, this paper demonstrates that the influence of the ion mobility, and the molecular mass of electrolyte is demonstrated to have a profound effect on the formation of the EDLC; where the higher molecular weights develop the double layer slower, result in a slightly poorer capacitive performance. 


\section{References}

1 Jiang, H. et al. High-rate electrochemical capacitors from highly graphitic carbon-tipped manganese oxide/mesoporous carbon/manganese oxide hybrid nanowires. Energy \& Environmental Science 4, 1813-1819, doi:10.1039/C1EE01032H (2011).

2 Wang, G., Zhang, L. \& Zhang, J. A review of electrode materials for electrochemical supercapacitors. Chemical Society Reviews 41, 797-828, doi:10.1039/C1CS15060J (2012).

Wang, Q., Yan, J. \& Fan, Z. Carbon materials for high volumetric performance supercapacitors: design, progress, challenges and opportunities. Energy \& Environmental Science 9, 729-762, doi:10.1039/C5EE03109E (2016).

Zhong, C. et al. A review of electrolyte materials and compositions for electrochemical supercapacitors. Chemical Society Reviews 44, 7484-7539, doi:10.1039/C5CS00303B (2015). Jiang, Y.-X., Li, J.-T., Sun, C.-F., Ren, B. \& Sun, S.-G. in Electrochemistry: Volume 12 Vol. 12 275335 (The Royal Society of Chemistry, 2014).

6 Xue, X., Wang, F. \& Liu, X. Emerging functional nanomaterials for therapeutics. Journal of Materials Chemistry 21, 13107-13127, doi:10.1039/C1JM11401H (2011).

7 Zhang, D., Du, X., Shi, L. \& Gao, R. Shape-controlled synthesis and catalytic application of ceria nanomaterials. Dalton Transactions 41, 14455-14475, doi:10.1039/C2DT31759A (2012).

8 Bonini, M., Baglioni, P. \& Chelazzi, D. in Nanoscience for the Conservation of Works of Art 315-344 (The Royal Society of Chemistry, 2013).

9 Li, Y.-F., Wang, L., Zhang, L. \& Chen, C. in Nuclear Analytical Techniques for Metallomics and Metalloproteomics 342-384 (The Royal Society of Chemistry, 2010).

10 Chen, L., Rende, D., Schadler, L. S. \& Ozisik, R. Polymer nanocomposite foams. Journal of Materials Chemistry A 1, 3837-3850, doi:10.1039/C2TA00086E (2013).

11 Studart, A. R. et al. Metallic foams from nanoparticle-stabilized wet foams and emulsions. Journal of Materials Chemistry 22, 820-823, doi:10.1039/C1JM14353K (2012).

12 He, S. \& Chen, W. 3D graphene nanomaterials for binder-free supercapacitors: scientific design for enhanced performance. Nanoscale 7, 6957-6990, doi:10.1039/C4NR05895J (2015).

13 Jiang, L. \& Fan, Z. Design of advanced porous graphene materials: from graphene nanomesh to 3D architectures. Nanoscale 6, 1922-1945, doi:10.1039/C3NR04555B (2014).

14 Chen, Z. et al. Three-dimensional flexible and conductive interconnected graphene networks grown by chemical vapour deposition. Nat Mater 10, 424-428, doi:http://www.nature.com/nmat/journal/v10/n6/abs/nmat3001.html\#supplementaryinformation (2011).

15 Chen, C.-M. et al. Macroporous 'bubble' graphene film via template-directed orderedassembly for high rate supercapacitors. Chemical Communications 48, 7149-7151, doi:10.1039/C2CC32189K (2012).

16 Choi, B. G., Yang, M., Hong, W. H., Choi, J. W. \& Huh, Y. S. 3D Macroporous Graphene Frameworks for Supercapacitors with High Energy and Power Densities. ACS Nano 6, 40204028, doi:10.1021/nn3003345 (2012).

17 Kampouris, D. K., Ji, X., Randviir, E. P. \& Banks, C. A new approach for the improved interpretation of capacitance measurements for materials utilised in energy storage. . RSC Advances 5, 12782-12791 (2015).

18 Chen, Z. et al. Three-dimensional flexible and conductive interconnected graphene networks grown by chemical vapour deposition. Nature Materials 10, 424-428, doi:doi: 10.1038/nmat3001. ( 2011 ).

19 Brownson, D. A. C., Kelly, P. J. \& Banks, C. E. In situ electrochemical characterisation of graphene and various carbon-based electrode materials: an internal standard approach. RSC Advances 5, 37281-37286, doi:10.1039/C5RA03049H (2015).

20 McCreery, R. Chem. Mater. 16, 4477 (2004). 
21 Woltornist, S. J., Carrillo, J.-M. Y., Xu, T. O., Dobrynin, A. V. \& Adamson, D. H. Polymer/Pristine Graphene Based Composites: From Emulsions to Strong, Electrically Conducting Foams. Macromolecules 48, 687-693, doi:10.1021/ma5024236 (2015).

22 Tiwari, A. \& Syväjärvi, M. Graphene Materials: Fundamentals and Emerging Applications. (Wiley, 2015).

23 Down, M. P., Foster, C. W., Ji, X. \& Banks, C. E. Pencil drawn paper based supercapacitors. RSC Advances 6, 81130-81141, doi:10.1039/C6RA18499E (2016).

24 Kampouris, D. K., Ji, X., Randviir, E. P. \& Banks, C. A new approach for the improved interpretation of capacitance measurements for materials utilised in energy storage. RSC Advances 5, 12782-12791 (2015).

25 Brownson, D. A. C. et al. Freestanding three-dimensional graphene foam gives rise to beneficial electrochemical signatures within non-aqueous media. Journal of Materials Chemistry A 1, 5962-5972, doi:10.1039/C3TA10727B (2013).

26 Zhang, S., Sun, N., He, X., Lu, X. \& Zhang, X. Physical Properties of lonic Liquids: Database and Evaluation. Journal of Physical and Chemical Reference Data 35, 1475-1517, doi:doi:http://dx.doi.org/10.1063/1.2204959 (2006).

27 Kim, T. Y. et al. High-Performance Supercapacitors Based on Poly(ionic liquid)-Modified Graphene Electrodes. ACS Nano 5, 436-442, doi:10.1021/nn101968p (2011).

28 Zhang, J., Jiang, J., Li, H. \& Zhao, X. S. A high-performance asymmetric supercapacitor fabricated with graphene-based electrodes. Energy \& Environmental Science 4, 4009-4015, doi:10.1039/C1EE01354H (2011).

29 Wu, Z.-S. et al. High-Energy $\mathrm{MnO} 2$ Nanowire/Graphene and Graphene Asymmetric Electrochemical Capacitors. ACS Nano 4, 5835-5842, doi:10.1021/nn101754k (2010).

30 Hong, M. S., Lee, S. H. \& Kim , S. W. Use of $\mathrm{KCl}$ Aqueous Electrolyte for $2 \mathrm{~V}$ Manganese Oxide/Activated Carbon Hybrid Capacitor. Electrochemical and Solid-State Letters 5, A227A230, doi:10.1149/1.1506463 (2002).

31 Chen, P.-C., Shen, G., Shi, Y., Chen, H. \& Zhou, C. Preparation and Characterization of Flexible Asymmetric Supercapacitors Based on Transition-Metal-Oxide Nanowire/Single-Walled Carbon Nanotube Hybrid Thin-Film Electrodes. ACS Nano 4, 4403-4411, doi:10.1021/nn100856y (2010). 
Figure 1 A) SEM images of the macrostructural properties of the freestanding 3D-G structure. Inset is an image of a damaged region, scratched delicately by a scalpel. The image in A) demonstrates the random tearing and structure of the freestanding 3D-G electrode, which arises due to the fabrication process (see experimental section). B) Raman spectra for the freestanding $3 \mathrm{D}-\mathrm{RVC}$ and $3 \mathrm{D}-\mathrm{G}$ over the range 500 to $3000 \mathrm{~cm}^{-1}$.

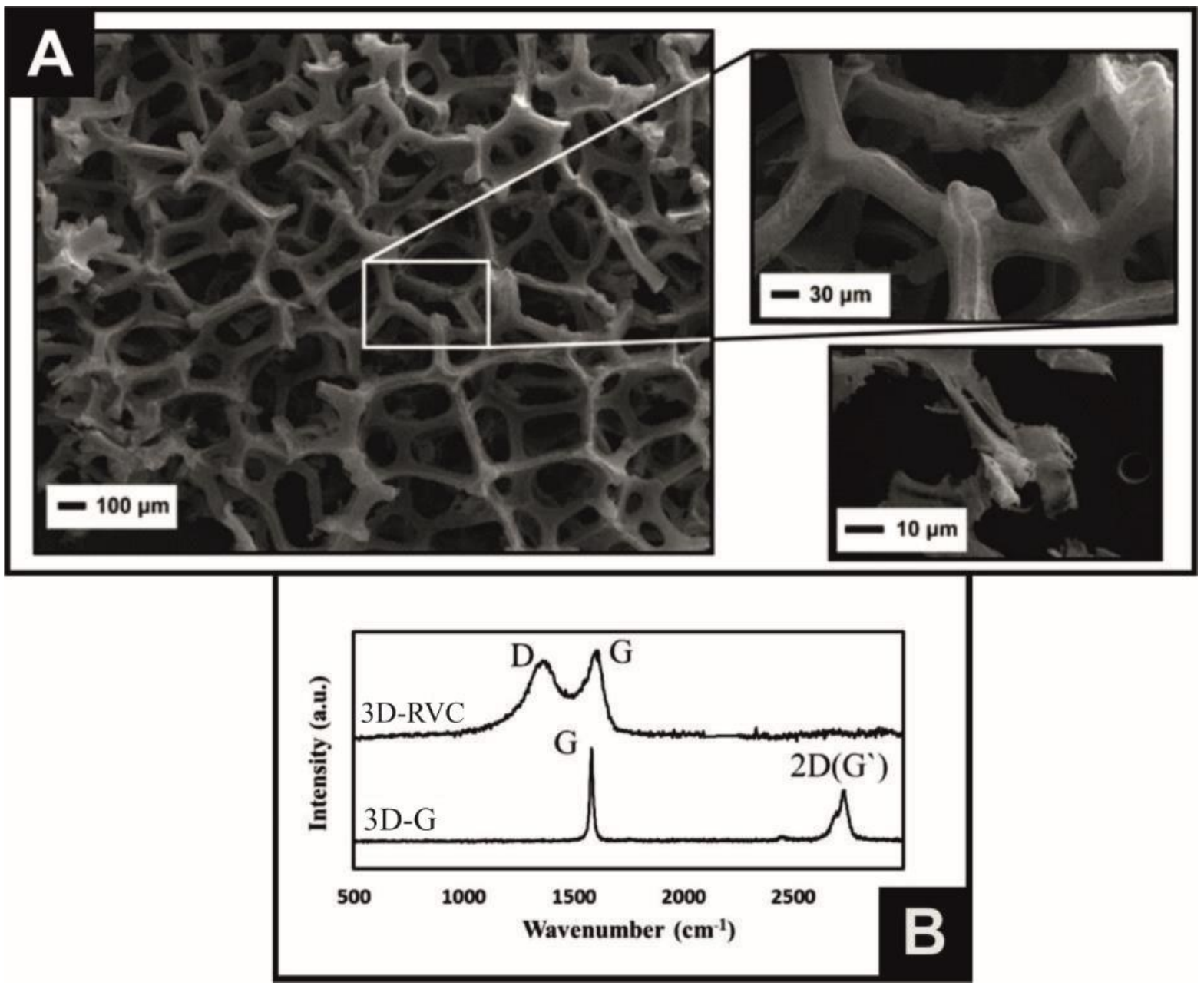


Figure 2 Capacitance analysis for the $3 \mathrm{D}-\mathrm{G}$ evaluated in a $0.1 \mathrm{M} \mathrm{H}_{2} \mathrm{SO}_{4}$ aqueous solution. A) Typical cyclic voltammetric response of the 3D-G examined within $0.1 \mathrm{M} \mathrm{H}_{2} \mathrm{SO}_{4}$ aqueous electrolyte; B) the charge-discharge cycles of the 3D-G with no parallel circuit in place, demonstrating the curved shape that generate ambiguity in the analysis and determination of the capacitance. C) the charge-discharge analysis with a $620 \mu \mathrm{F}$ capacitor in parallel with the 3D-G, demonstrating a significant improvement of the linearity of the potential response; D) The capacitance for both the 3D-RVC and the 3D-G.

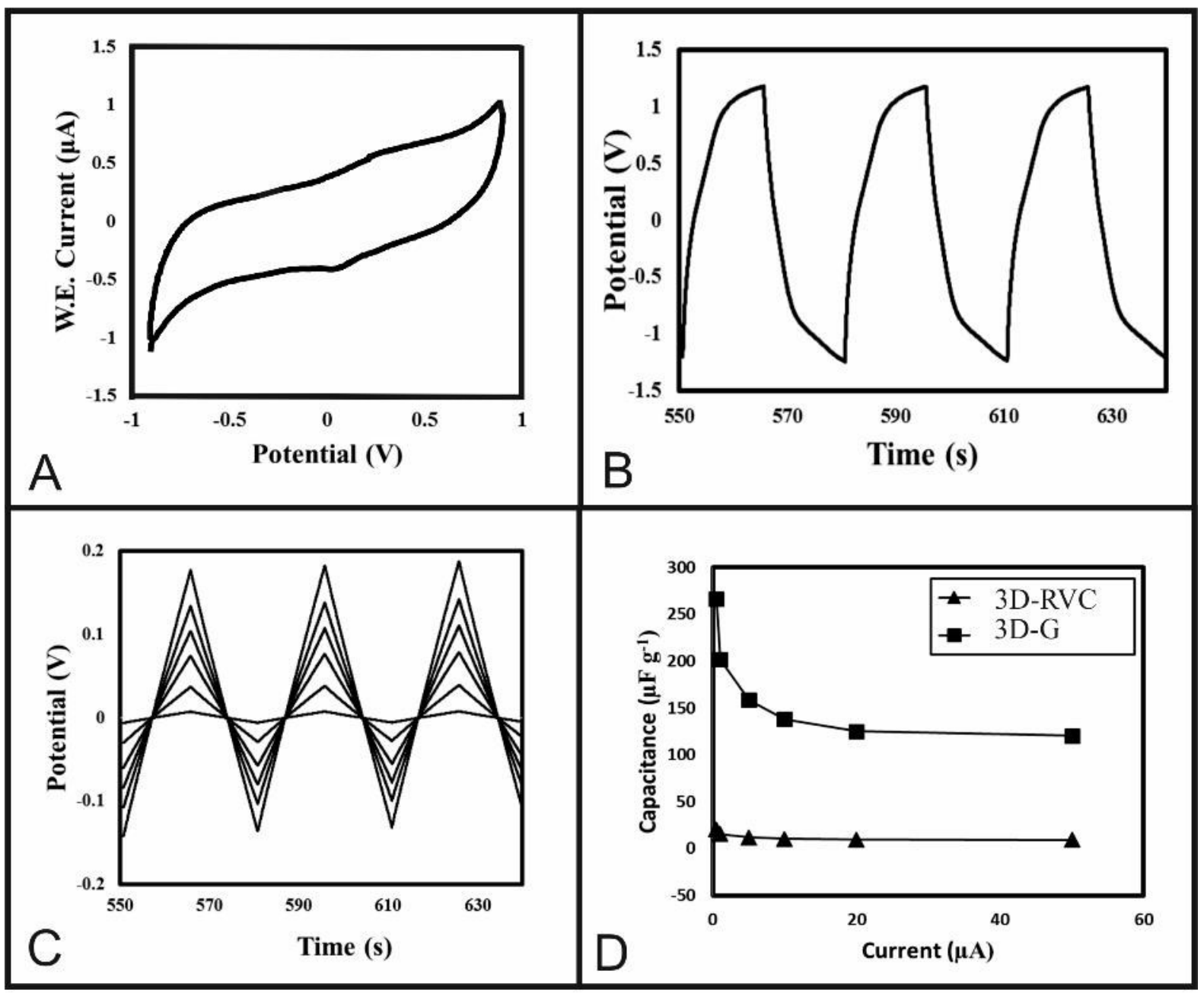


Figure 3 The charge-discharge behaviours for the 3D-G examined within a range of ionic liquids, with no parallel capacitor to demonstrate the natural potential evolution of the system. The cycles displayed are the $23^{\text {rd }}, 24^{\text {th }}$ and $25^{\text {th }}$.

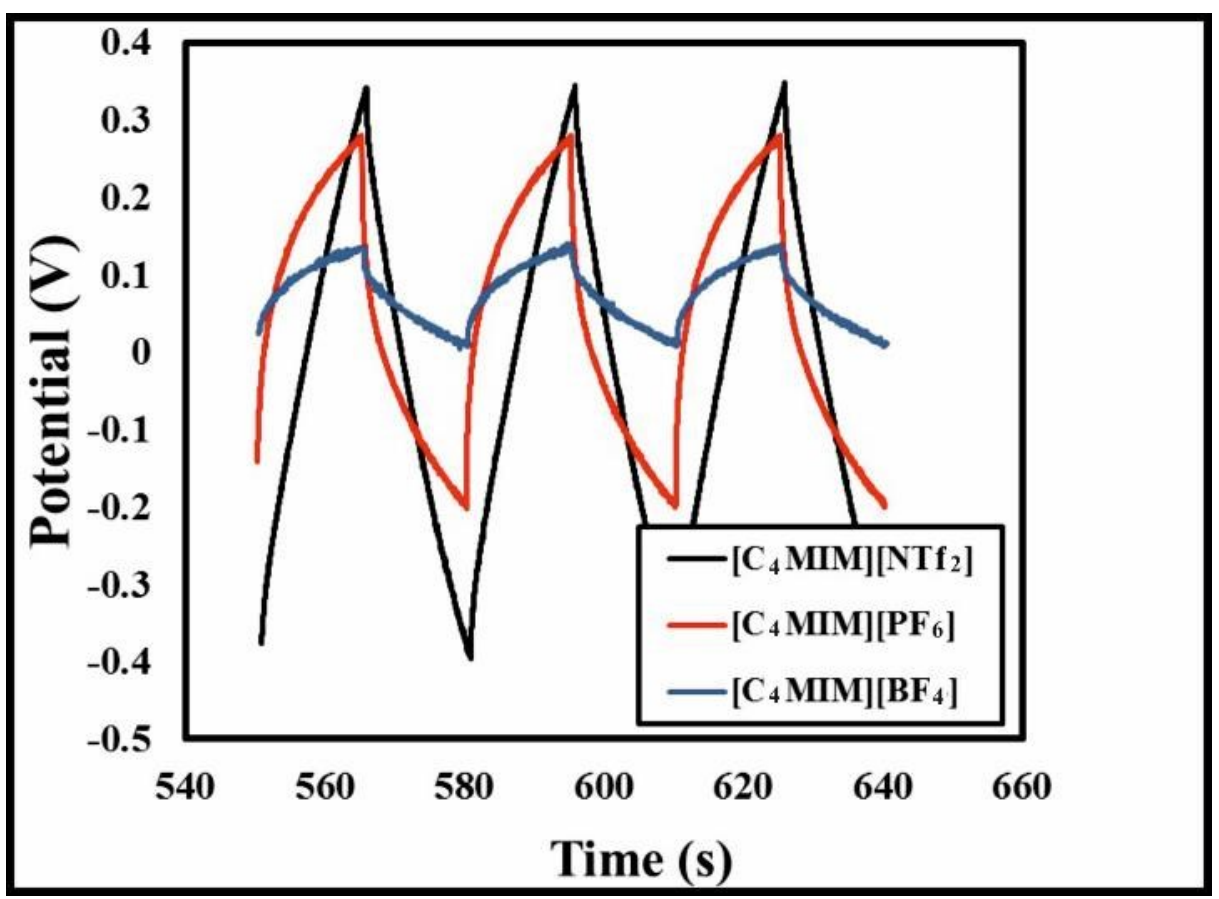


Figure 4 Left: The performance of the 3D-G in each of the ionic liquids in terms of capacitance. Right: The relative capacitive performance of the 3D-G, nickel and 3D-RVC examined in $\left[\mathrm{C}_{4} \mathrm{MIM}\right]\left[\mathrm{BF}_{4}\right]$.

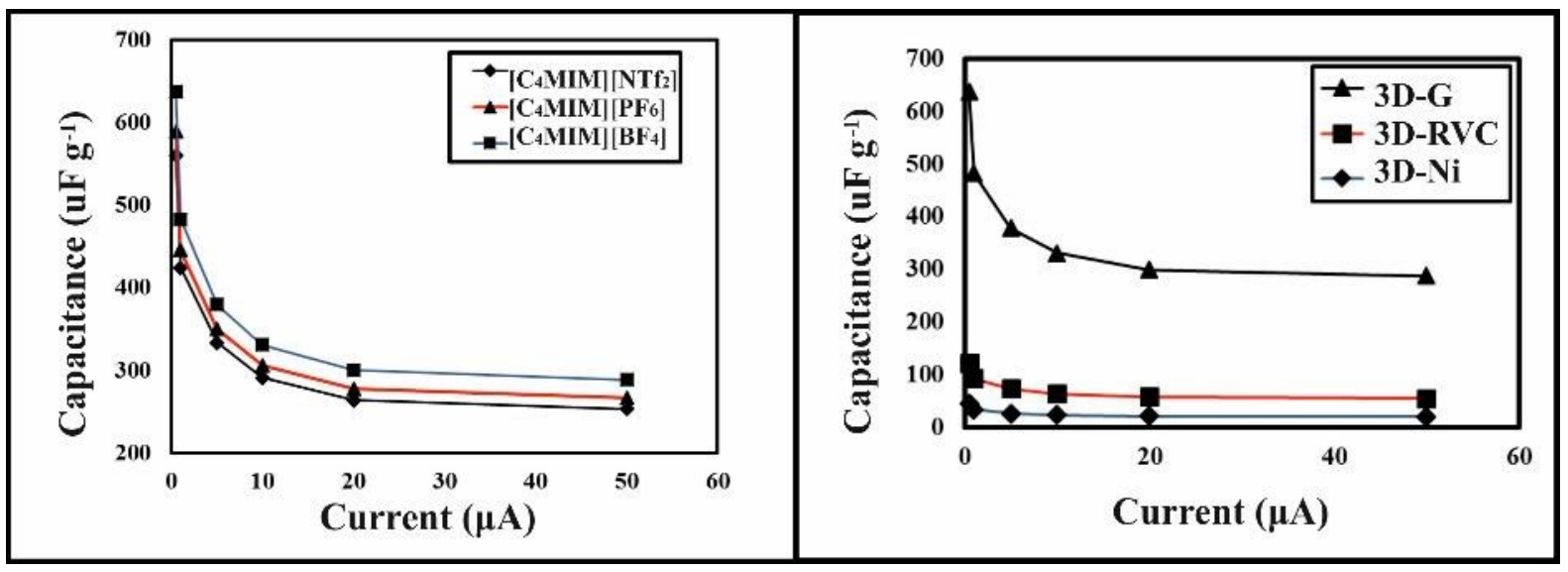


Figure 5. The Ragone plot, showing the Energy and Power densities of the 3D-G in context to other similar materials and studies. The resulting performance demonstrates values at the higher end of both the energy and power in the spectrum normally considered the norm for supercapacitors. The resulsts here are compare to Poly (Ionic Liquid) - Modified reduced graphene oxide electrodes ${ }^{27}$; a symmetrical graphene based supercapacitor ${ }^{28}$; a symmetrical supercapacitor using reduced graphene oxide, modified with ruthenium oxide and polyaniline ${ }^{29}$; An asymmetric supercapacitors of graphene and $\mathrm{MnO}_{2}$ nanowires; a manganese oxide activated carbon hybrid capacitor $^{30}$; a supercapacitor utilising metal oxide nanowires/carbon nanotube thin film electrodes ${ }^{31}$.

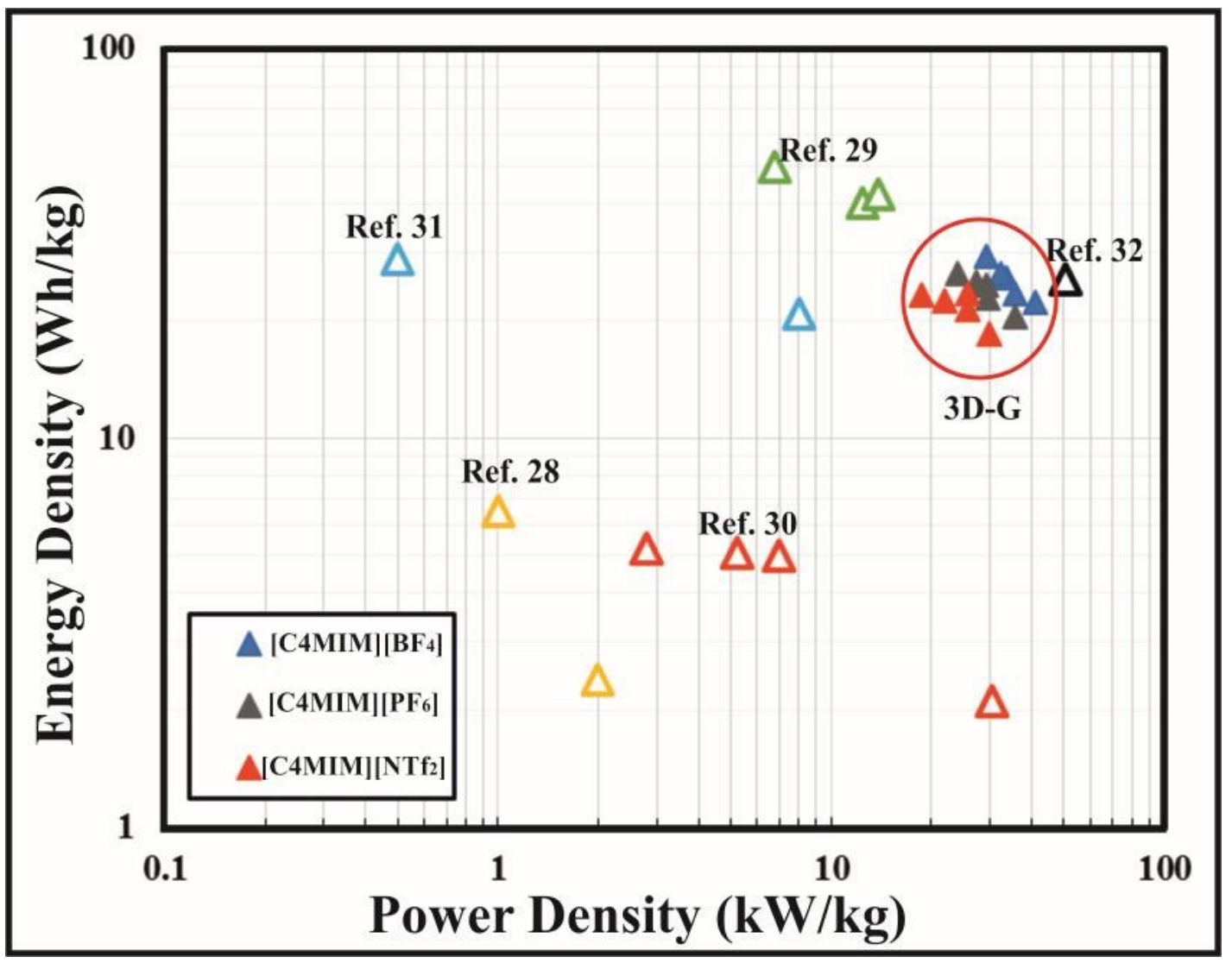




\section{Electronic Supplementary Information (ESI)}

ESI Figure 1 SEM images of the nickel macrostructure, onto which the graphene is grown via a CVD process to form the $3 \mathrm{D}-\mathrm{G}$.

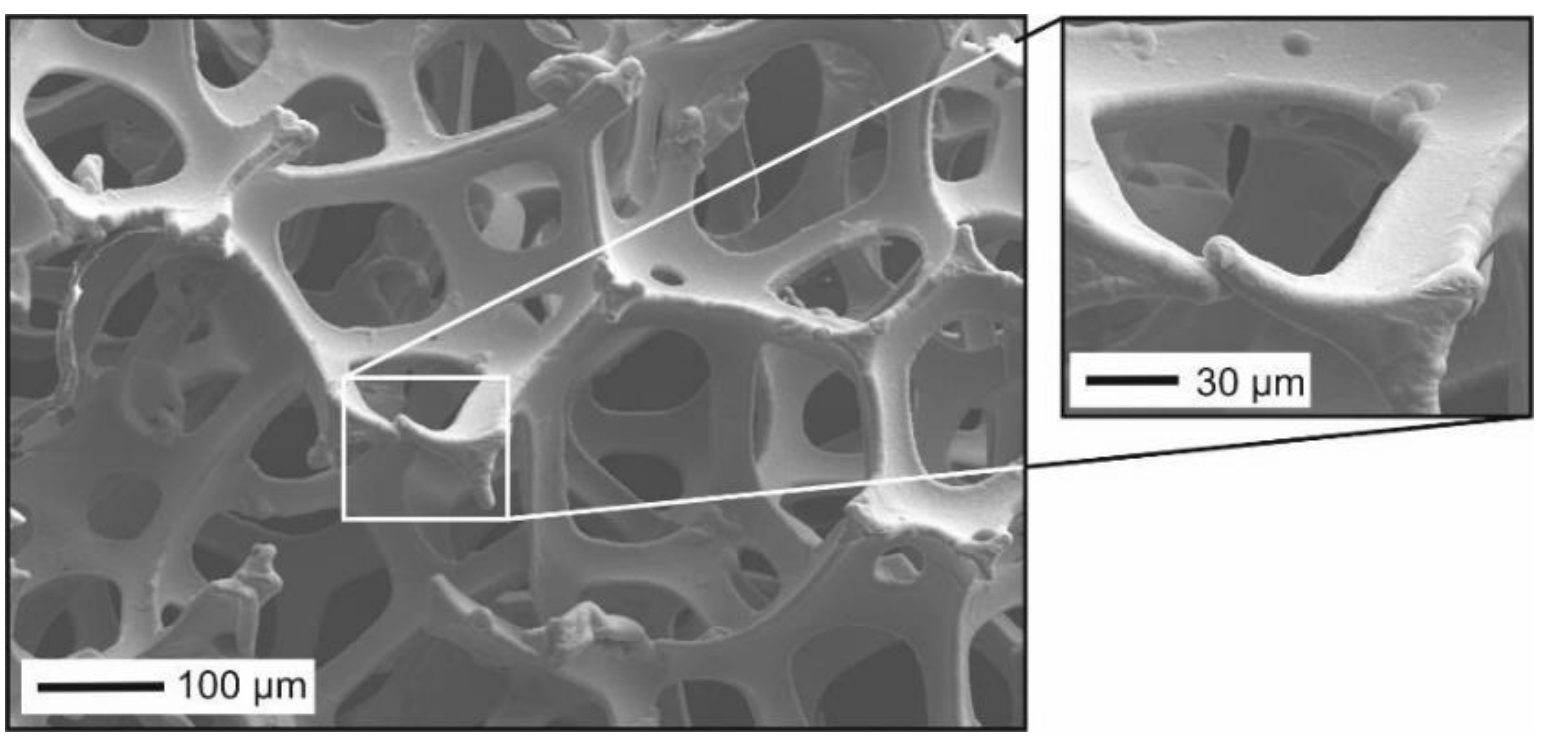


ESI Figure 2. SEM images of the 3D-RVC freestanding macrostructure, insert is a scaled photograph of the 3D-RVC's macrostructure.

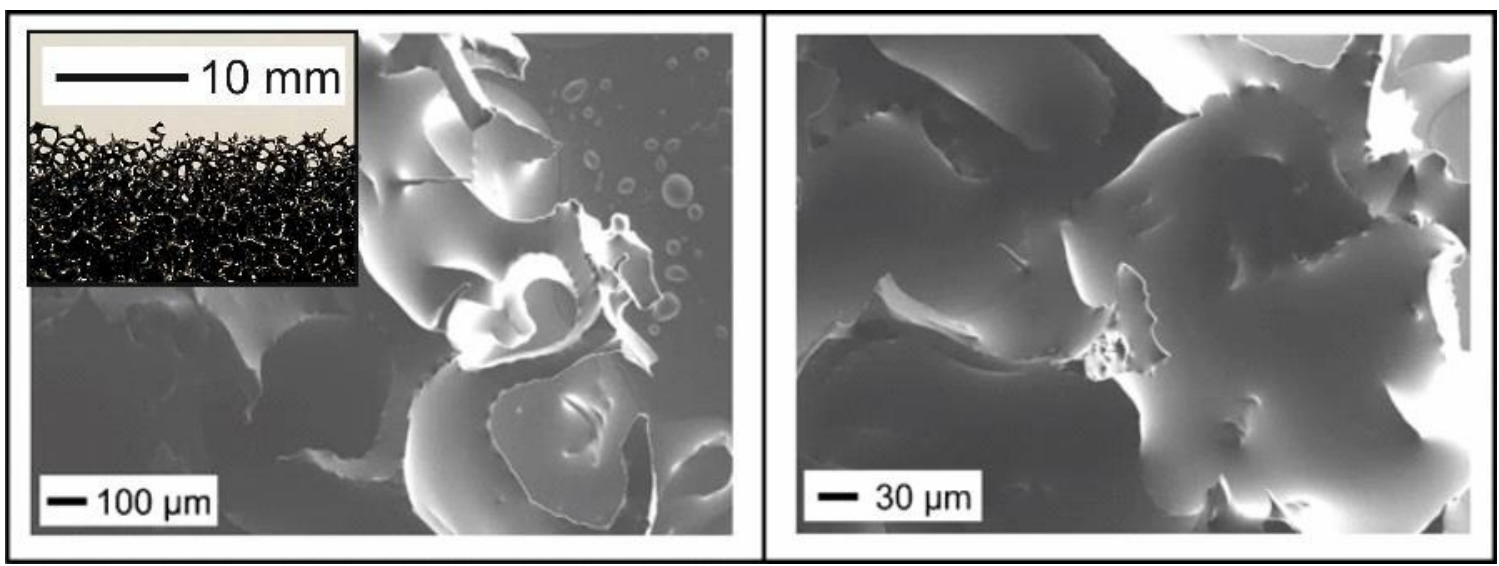


ESI Figure 3. Typical cyclic voltammograms obtained using the $3 D-G$ electrode material recorded in the following ionic liquids: $\left[\mathrm{C}_{4} \mathrm{MIM}\right]\left[\mathrm{NTf}_{2}\right]$ (dotted); $\left[\mathrm{C}_{4} \mathrm{MIM}\right]\left[\mathrm{PF}_{6}\right]$ (solid) and $\left[\mathrm{C}_{4} \mathrm{MIM}\right]\left[\mathrm{BF}_{4}\right]$ (dashed).

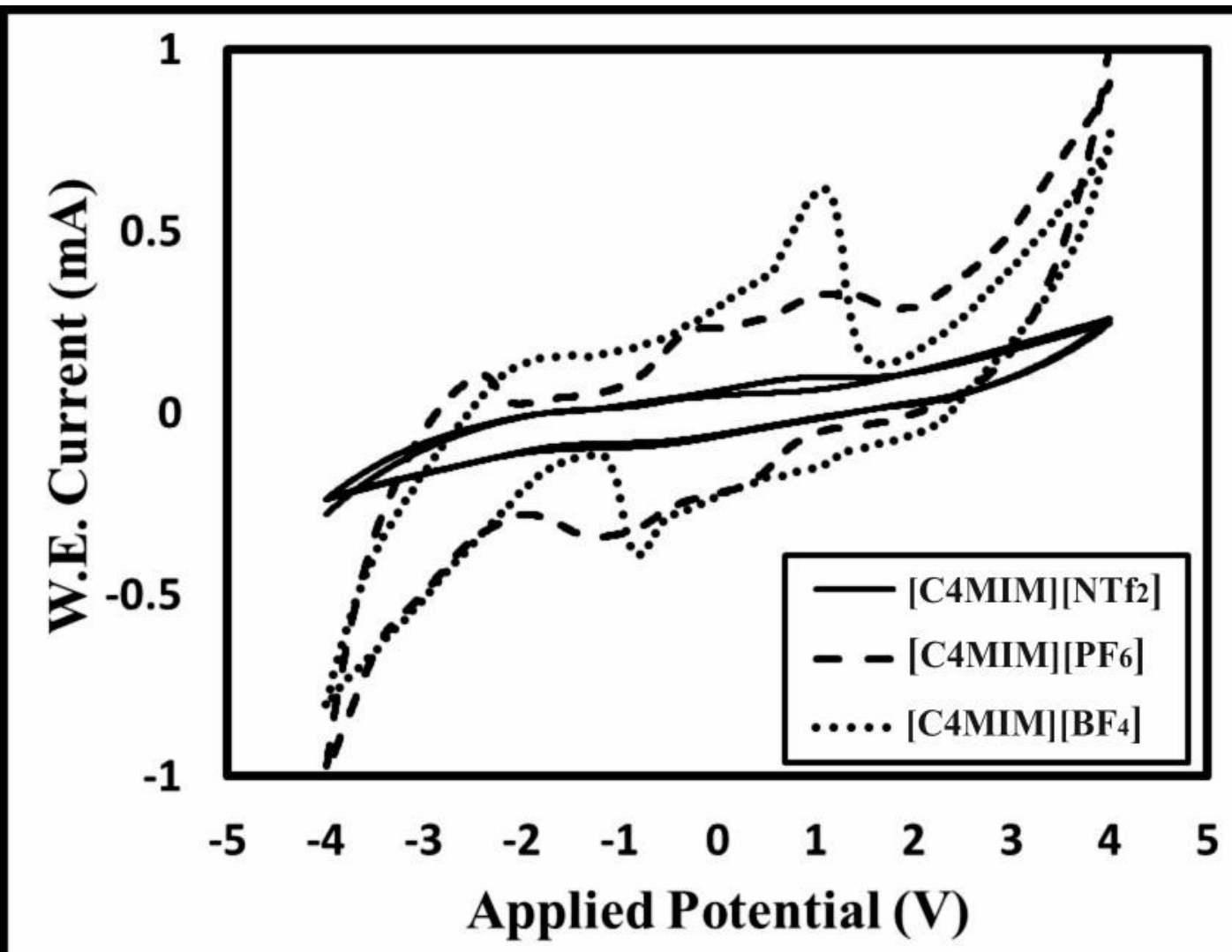


ESI Figure 4. Capacitance retention of the freestanding electrodes in $\left[\mathrm{C}_{4} \mathrm{MIM}\right]\left[\mathrm{BF}_{4}\right]$ for 5000 cycles, $15 \mathrm{~s}$ switching period and $0.5 \mu \mathrm{A}$. Any cycling instability of the freestanding graphene and nickel macrostructures are completely overcome by the evident 'wicking' of electrolyte into the macrostructures and the resulting increase in surface area. This is not seen in the case of the 3D-RVC, which demonstrates a more typical decline in performance, decreasing by roughly $1.2 \%$ over 5000 cycles.

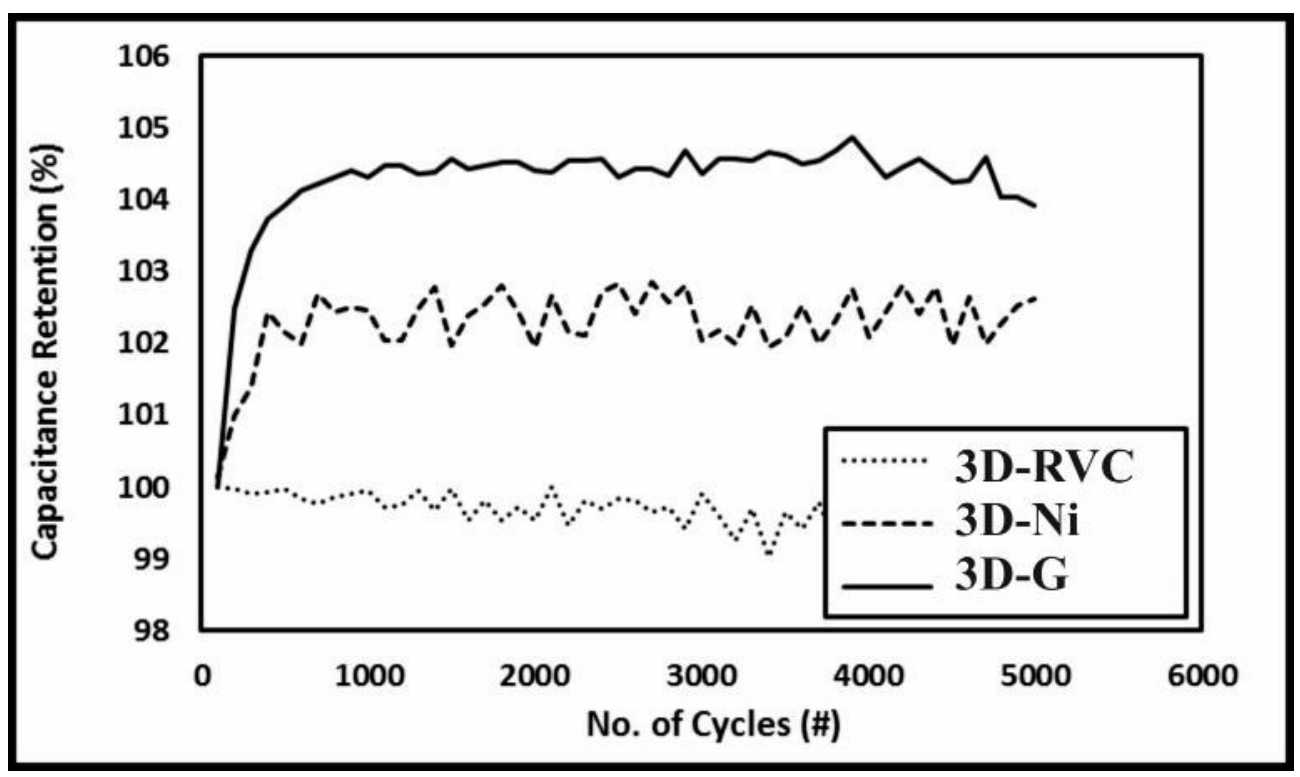

